\title{
Endosonography-Guided Fine-Needle Aspiration versus "Key-Hole Biopsy" in the diagnostics of upper gastrointestinal subepithelial tumors. A prospective randomized interventional study
}

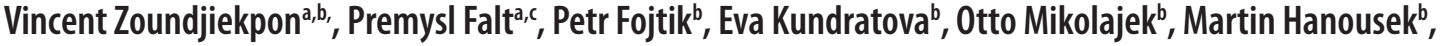 \\ Katerina Reiterovad ${ }^{d}$, Dusan Ziak ${ }^{\mathrm{e}}$, Martin Bolek ${ }^{\mathrm{f}}$, Anicet Tchibozo ${ }^{\mathrm{g}}$, Martin Kliment ${ }^{\mathrm{h}}$, Ondrej Urban ${ }^{\mathrm{a}}$
}

Background. The management and prognosis of subepithelial tumors (SETs) of the upper gastrointestinal tract depend on the correct preoperative evaluation, including tissue diagnosis in selected cases. Several methods providing deep tissue sampling for cytological and/or histological examinations have been described but their diagnostic yield and precise position in the diagnostic algorithm remain to be established. This prospective randomized study aims to compare the Endosonography-Guided Fine-Needle Aspiration (EUS-FNA) to Key-Hole Biopsy (KHB) in cytological or histological diagnostics of upper gastrointestinal SETs.

Patients and Methods. This study was conducted in a single tertiary endoscopy center in Ostrava, Czech Republic between November 2010 and October 2015. Patients with endoscopically detected SETs of the upper gastrointestinal tract with a diameter $\geq 2 \mathrm{~cm}$, were randomized to either the EUS-FNA with $22 \mathrm{G}$ needle, or to the Key Hole biopsy (forceps biopsy through mucosal incision) groups. The main study outcomes were success rate of tissue diagnostics and, in the cases of Gastrointestinal Stromal Tumours (GIST), possibility of determining mitotic activity. A cross-over examination was performed in situations where the first method had failed.

Results. A total of 46 consecutive patients were randomized. Of these, 24 (52\%) and 22 (48\%) were randomized to EUS-FNA group and KHB arm, respectively. 5 SETs (11\%) were detected in the esophagus, $40(87 \%)$ in the stomach and $1(2 \%)$ in the duodenum. The definitive diagnosis was established by the first sampling method in 42 (91\%) patients, including $22(92 \%)$ in the EUS-FNA group and $20(91 \%)$ in the KHB group $(P=0.999)$, and after a cross-over in another $3(7 \%)$ patients. The most prevalent SET was GIST (70\%). Although some mitotic activity could be observed in 11 patients, the mitotic index could be diagnosed in none of them. Of a total of 20 surgically treated patients, preoperative and postoperative tissue diagnosis corresponded in 19/20 (95\%) cases, including 100\% in FNA group and $91 \%$ in KHB group $(P=0.999)$. No adverse events of tissue sampling occurred in the study.

Conclusions. Deep tissue sampling by EUS-FNA and KHB are equally effective in the diagnostics of SETs of the upper gastrointestinal tract $\geq 2 \mathrm{~cm}$. However, neither EUS-FNA nor KHB provided adequate tissue sample to determine mitotic index.

Trial Registration: Clinicaltrials.gov (NCT02025244).

Key words: upper gastrointestinal subepithelial tumors, endosonography-guided fine-needle aspiration, key-hole biopsy, gastrointestinal stromal tumors, mitotic activity, mitotic index

Received: November 11, 2018; Accepted with revision: April 2, 2019; Available online: April 17, 2019

https://doi.org/10.5507/bp.2019.013

(c) 2020 The Authors; https://creativecommons.org/licenses/by/4.0/

a Department of Internal Medicine II - Gastroenterology and Geriatric, Faculty of Medicine and Dentistry, Palacky University Olomouc and University Hospital Olomouc, Czech Republic

${ }^{b}$ Digestive Diseases Center, Vitkovice Hospital, Ostrava, Czech Republic

'Faculty of Medicine, Charles University in Hradec Kralove, Czech Republic

${ }^{d}$ Biopsy and Cytology Department, Agel Laboratories, Novy Jicin, Czech Republic

${ }^{e}$ CGB Laboratories, Ostrava, Czech Republic

fDepartment of Surgery, Vitkovice Hospital, Ostrava, Czech Republic

${ }^{9}$ StatMed-Health Analytics \& Business Intelligence, Saint-Jean Sur Richelieu, Quebec, Canada

${ }^{h}$ Department of Internal Medicine, Gastroenterology and Hepatology-Vivantes Clinic, Berlin, Germany

Corresponding author: Vincent Zoundjiekpon, e-mail:zovinc@hotmail.com

\section{INTRODUCTION}

Subepithelial tumors (SETs) of the upper gastrointestinal tract originate from any subepithelial layer of the esophageal, gastric or duodenal wall, mostly from submucosa and muscularis propria ${ }^{1,2}$. SETs are frequently discovered incidentally during upper gastrointestinal endoscopy for other reasons ${ }^{3}$. Nevertheless, some of them may be symptomatic due to their size, localization or bleeding. The estimated prevalence of SETs around 0.33\% at routine upper endoscopy has been reported ${ }^{4}$. Recently, an increasing detection rate has been shown that can be 
attributed to advanced diagnostic techniques capable of detecting small lesions and higher attention paid to these lesions ${ }^{2}$. Although the endoscopic appearance of SETs is similar, they differ both histologically and biologically. Endoscopic ultrasonography (EUS) proved effective in the differential diagnostics of SETs. EUS may differentiate intra- from extramural lesions and provides information about the layer of origin and its echostructure ${ }^{5-8}$. Despite this advantage, tissue sampling is usually necessary to confirm the diagnosis as shown by previous studies ${ }^{9-13}$.

As a rule, standard forceps biopsy of the lesion overlying mucosa is inconclusive. Therefore, deep biopsies are advocated $^{14,15}$. Several methods of deep biopsy including "biopsy on biopsy" and jumbo forceps biopsy are described in the literature. Nevertheless, no consensus about their usage has been achieved until now ${ }^{12,14,16-18}$. Moreover, new sampling strategies, including Key-Hole Biopsy (KHB) which consists of forceps biopsy through mucosal incision with a needle knife, have been reported ${ }^{8,19}$.

The primary aim of this study was to compare success rate of tissue diagnostics using EUS-FNA with $22 \mathrm{G}$ needle to KHB of upper gastrointestinal SETs with diameter $\geq 2 \mathrm{~cm}$. Secondary aim was to evaluate the feasibility to use these methods for the determination of mitotic index in the case of GIST.

\section{PATIENTS AND METHODS}

This study was conducted in a single tertiary endoscopy center in Ostrava, Czech Republic in the period from November 2010 to October 2015. It was approved by the local ethics committee (Institutional Review Board Number EK27612) and registered at Clinicaltrials.gov (NCT02025244).

All consecutive patients with endoscopically detected SETs of the upper gastrointestinal tract with diameters $\geq 2$ cm (Fig. 1) were enrolled and considered for randomization according to the trial 's criteria. All enrolled patients signed informed consent.

Exclusion criteria were age $<18$ years, tumor size $<20$ $\mathrm{mm}$, pregnancy and significant coagulopathy.

All enrolled patients underwent radial EUS examination (GF - UE 160, Olympus Medical systems, Hamburg, Germany and Aloka Pro Sound Alpha 10 ultrasound system). In cases of stomach or duodenal lesions, EUS water immersion method was used while, in the case of oesophageal lesions, balloon method was employed. The lesion size, layer of origin and EUS characteristics were examined. Following radial EUS, the randomization to either EUS-FNA group or KHB group was performed using random sequences generated by a computer software program.

Both EUS-FNA and KHB were performed in a standardized manner with the patients under conscious sedation using midazolam (2-5 mg), butylscopolamine (20-40 $\mathrm{mg})$ and fentanyl $(50-100 \mu \mathrm{g})$.

EUS- FNA (Fig. 2) was performed with a linear array echoendoscope (GF- UCT 180 or GF - UCT 140, Olympus Medical System, Hamburg, Germany and Aloka
ProSound Alpha 10) using a standard 22-gauge fine needle (Expect TM, Boston scientific, Natick, Massachusetts or EZ Shot NA-220H-8019/8022, Olympus Medical system, Hamburg, Germany). Before puncturing, the lesion was visualised in B- mode, in order to confirm the absence of intervening blood vessels by means of color Doppler. After lesion puncture the stylet was withdrawn and the needle was moved back and forth 5-8 times within the lesion in a fan-like manner. Four to five series of punctures in different regions of the tumors were performed (1-2× with suction 5-10 Torr with an empty syringe). Punctures through the peritoneum was avoided. After the needle withdrawal, the specimen was pushed out from the needle on the microscope slide and vial with $10 \%$ formalin solution by stylet re-insertion. Rapid On-Site Evaluation (ROSE) of the samples was not available.

KHB (Fig. 3, Fig 4a. - 4g.) was performed using standard gastroscopes (GIF- HQ 190, GIF- 180 or GIF180J, Olympus, Hamburg, Germany). A $5 \mathrm{~mm}$ incision ("keyhole") of the mucosa overlying SET was made using a needle knife - length $5 \mathrm{~mm}$ (V-System Single-Use TripleLumen Needle-Knives, Olympus, Hamburg Germany). Deep forceps biopsy (single- use forceps Jaw 4, Boston Scientific, Natick, Massachusetts, USA) through the hole was then performed. Five to seven samples were taken from different parts of the tumor. After the sampling, the mucosal incision was closed using endoscopic clips.

Following the procedures, patients were kept under observation for $24 \mathrm{~h}$. Both CRP level and blood count were checked $4 \mathrm{~h}$ after the procedure.

Specimen obtained via EUS-FNA were processed in the form of cytological smears stained by the method of May - Gruenwald - Giemsy (MGG QUICK STAIN 04 - 090805 - Bio - optical) and the Periodic Acid Schiff (PAS). Part of the material was processed as a routine cell block, whereby a fixed pellet of material from a fine needle was sealed in a paraffin block, and processed using the method of biopsy, including attempt of performing an immunohistochemical analysis (Table 1).

The material of the KHB was fixed in $10 \%$ neutral- buffered formalin and sealed in paraffin blocks. Subsequently, tissue sections were stained with hematoxylin and eosin and used for routing histological and immunohistochemical analysis (Table 1).

The procedure was considered successful when tissue sample sufficient to make a histological diagnosis was obtained. In the case of failure of the initial method, the alternative method was performed.

Mitotic activity defined as a number of mitoses in 50 high-power-fields, was examined in the case of GIST.

\section{Statistical analysis}

R Programming and NCSS 2007 (Kaysville, Utah, USA) were used for statistical analyses. Differences between independent proportions of SETs diagnosed by EUS-FNA and KHB, respectively, were compared using the binomial exact test. Proportions of SETs across sites and types of diagnosis were calculated. Differences between subcategories were compared using the chi-square statistic while Fisher's exact test was used, if the expected 
Table 1. Immunohistochemical markers used to confirm the diagnosis of subepithelial tumors.

\begin{tabular}{ll}
\hline Typ of used immunohistochemical marker & Typ of detected subepithelial tumors \\
\hline CD 117, DOG-1 & GIST \\
CD 34, S100 proteins,PDGFRA & GIST \\
SMA & Leiomyoma \\
Desmin & Leiomyoma \\
CD20, CD25 & Lymphoma(MALT) \\
CK 20 & Adenocarcinoma \\
CDX2 & adenocarcinma \\
CD56, Chromogranin A, Synaptofyzin & NET \\
\hline
\end{tabular}

CD (Cluster of differentiation), PDGFRA (platelet-derived growth factor receptor-alpha), DOG - 1 (Discovered On GIST-1), SMA (smooth muscle actin), desmin, S100 proteins, CK (CytoKeratin), CDX2 (Homeobox protein), GIST (Gastrointestinal Stromal tumors), NET (Neuroendocrine tumor)

Table 2. Baseline Characteristics of the study.

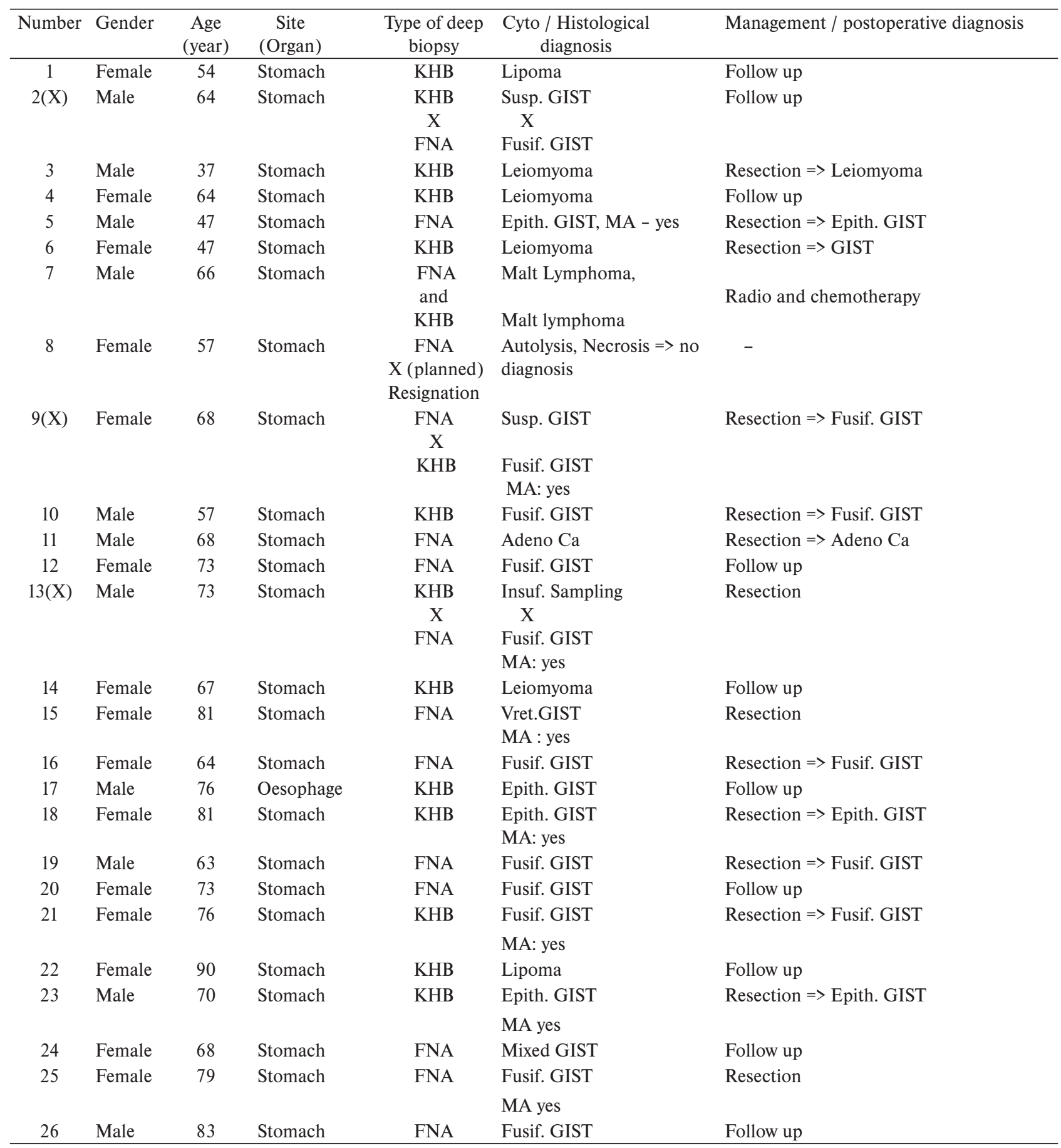


Table 2. (Continued)

\begin{tabular}{|c|c|c|c|c|c|c|}
\hline Number & Gender & $\begin{array}{l}\text { Age } \\
\text { (year) }\end{array}$ & $\begin{array}{c}\text { Site } \\
(\text { Organ })\end{array}$ & $\begin{array}{c}\text { Type of deep } \\
\text { biopsy }\end{array}$ & $\begin{array}{c}\text { Cyto / Histological } \\
\text { diagnosis }\end{array}$ & Management / postoperative diagnosis \\
\hline 27 & Female & 68 & Stomach & KHB & GIST & Follow up \\
\hline 28 & Male & 57 & Stomach & КHB & $\begin{array}{l}\text { Mixed GIST } \\
\text { MA yes }\end{array}$ & Prefered Follow up \\
\hline 29 & Female & 77 & Stomach & FNA & Fusif. GIST & Follow up \\
\hline 30 & Male & 68 & Oesophage & FNA & Leiomyoma & Follow up \\
\hline 31 & Female & 67 & Oesophage & FNA & Leiomyoma & Follow up \\
\hline 32 & Female & 66 & Stomach & КHB & Mixed GIST & Follow up \\
\hline 33 & Male & 76 & Oesophage & FNA & Fusif. GIST & Follow up \\
\hline 34 & Male & 70 & Stomach & FNA & Fusif. GIST & Follow up \\
\hline 35 & Female & 30 & Stomach & КHB & Mixed GIST & Resection \\
\hline & & & & & MA yes & \\
\hline 36 & Female & 61 & Stomach & FNA & Fusif. GIST & * Neoadj.th + resection $\Rightarrow>$ Fusif. GIST \\
\hline 37 & Female & 71 & Oesophage & FNA & Leiomyoma & Follow up \\
\hline 38 & Male & 41 & Stomach & КHB & Fusif. GIST & Resection $\Rightarrow>$ Fusif. GIST \\
\hline 39 & Female & 71 & Stomach & FNA & Fusif. GIST & Follow up \\
\hline 40 & Female & 64 & Stomach & КНB & NET-G1 & Resection \\
\hline 41 & Male & 50 & Stomach & FNA & Fusif. GIST & Follow up \\
\hline 42 & Female & 69 & Stomach & FNA & Fusif. GIST & Follow up \\
\hline 43 & Male & 86 & Stomach & КНB & GIST & Resection $\Rightarrow$ Fusif GIST \\
\hline & & & & & MA yes & \\
\hline 44 & Male & 74 & Stomach & FNA & Mixed GIST & Resection $\Rightarrow>$ Mixed GIST \\
\hline 45 & Male & 73 & Duodenum & КНB & inflammatory fibroid polyp & Follow up \\
\hline 46 & Male & 56 & Stomach & KHB & GIST & Follow up \\
\hline
\end{tabular}

$\mathrm{X}=$ cross-over, FNA = Endosonography-Guided Fine-Needle Aspiration, KHB = Key-Hole biopsy, MA = Mitotic Activity, GIST = Gastrointestinal Stromal Tumor, Fusif. $=$ Fusiform, Epith. $=$ Epitheloid, NET = Neuroendocrine Tumor, Adeno Ca = Adenocarcinoma

Table 3. Area and type of diagnosed subepithelial tumors (SETs).

\begin{tabular}{|c|c|c|c|c|c|}
\hline \multirow{2}{*}{ Area and Type of SETs } & \multicolumn{3}{|c|}{ Tissue } & \multicolumn{2}{|c|}{ Exact Fisher } \\
\hline & $\mathrm{n}$ & $\begin{array}{c}\text { Diagnosed } \\
\mathrm{n}(\%)\end{array}$ & $\begin{array}{c}\text { Not diagnosed } \\
\mathrm{n}(\%)\end{array}$ & Chi-Square & $P$ \\
\hline $\begin{array}{l}\text { Area of primary } \\
\text { diagnosed SETs }\end{array}$ & & & & 90.07 & $<0.001$ \\
\hline Esophagus & 46 & $5(11)$ & $41(89)$ & & \\
\hline Stomach & 46 & $40(87)$ & $6(13)$ & & \\
\hline Duodenum & 46 & $1(2)$ & $45(98)$ & & \\
\hline Type of SETs & & & & 75.82 & $<0.001$ \\
\hline GIST & 46 & $32(70)$ & $14(30)$ & & \\
\hline Leiomyoma & 46 & $7(15)$ & $39(85)$ & & \\
\hline Lipoma & 46 & $2(4)$ & $44(96)$ & & \\
\hline Malt Lymphoma & 46 & $1(2)$ & $45(98)$ & & \\
\hline Adenocarcinoma & 46 & $1(2)$ & $45(98)$ & & \\
\hline Infl. Fibroid polyp & 46 & $1(2)$ & $45(98)$ & & \\
\hline Neuroendocrine tumor & 46 & $1(2)$ & $45(98)$ & & \\
\hline No dg & 46 & $1(2)$ & $45(98)$ & & \\
\hline
\end{tabular}

value of a cell was less than 5. Pairwise comparisons were adjusted using Marascuilo's multiple comparison test ${ }^{20}$. For all analyses, $P<0.05$ was defined as statistically significant.

\section{RESULTS}

During a study period a total of 52 patients with upper gastrointestinal SETs were enrolled in the study. Of them 46 were randomized (Table 2, study Flow diagram). The location of SETs were as follows n (\%): Esophagus of 5 (11) stomach of 40 (87) and duodenum of 1(2) pa- 
Table 4. Comparison of EUS-FNA and KHB in preoperative and postoperative diagnostics of upper gastrointestinal SETs (EUS-FNA vs KHB).

\begin{tabular}{|c|c|c|c|c|c|c|}
\hline \multirow[b]{2}{*}{ Analyses } & \multicolumn{3}{|c|}{ Diagnostic Method } & \multicolumn{3}{|c|}{ Exact Binomial } \\
\hline & $\mathrm{n}$ & $\begin{array}{c}\text { EUS-FNA } \\
P \% \text { (n/total) }\end{array}$ & $\begin{array}{c}\text { KHB } \\
P \%(\text { n/total })\end{array}$ & Difference \pm SE & $\begin{array}{c}95 \% \mathrm{CI} \\
\text { (Miettinen) }\end{array}$ & $P$ \\
\hline Primary dg SETs & 46 & $92(22 / 24)$ & $91(20 / 22)$ & $0.01 \pm 0.08$ & {$[-0.19 ; 0.21]$} & 0.999 \\
\hline Dg after cross-Over & 47 & $92(24 / 26)$ & $91(21 / 23)$ & $0.01 \pm 0.08$ & {$[-0.17 ; 0.20]$} & 0.999 \\
\hline POTIDIC & 19 & $100(9 / 9)$ & $91(9 / 10)$ & $0.10 \pm 0.98$ & {$[-0.23 ; 0.41]$} & 0.999 \\
\hline Supposed MA & 32 & $21(4 / 19)$ & $54(7 / 13)$ & $-0.32 \pm 0.17$ & {$[-0.61 ; 0.01]$} & 0.042 \\
\hline
\end{tabular}

$\mathrm{SE}=$ Standard Error estimated of the difference, 95\% CI= 95\% Confidence Intervals, MA = Mitotic Activity, POTIDIC= Postoperative Tissue Diagnosis Correspondence.

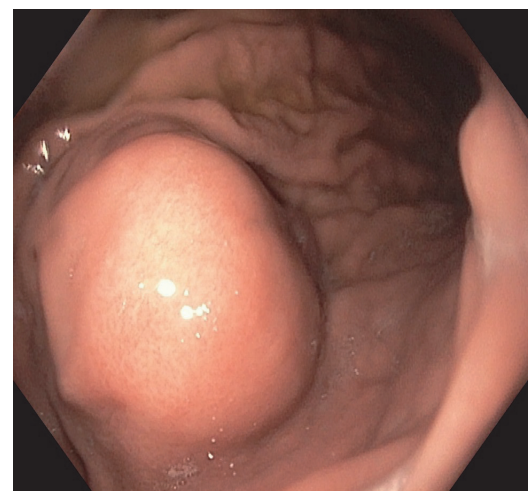

Fig. 1. Gastric subepithelial tumor-gastroscopy.

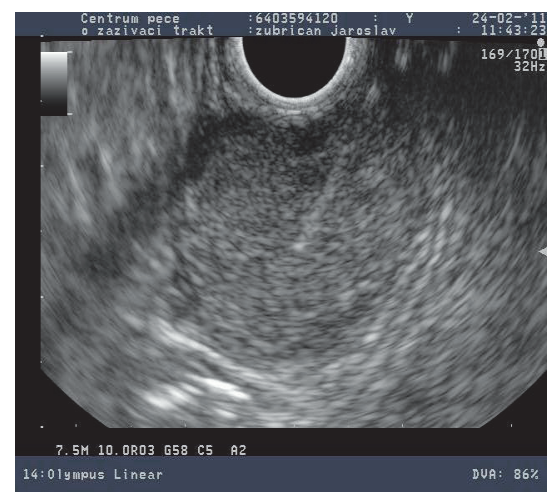

Fig. 2. Endosonography-guided aspiration.

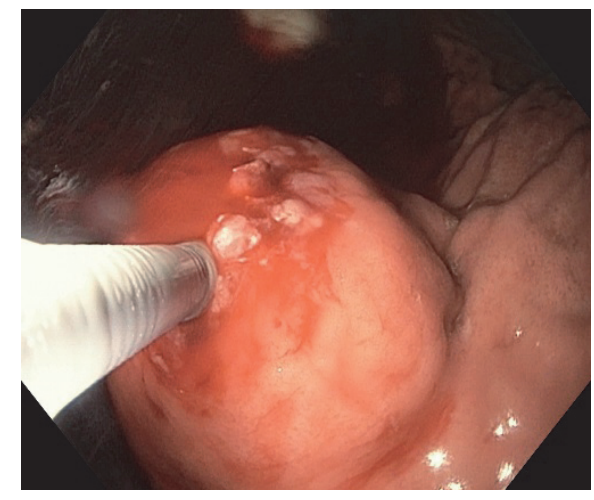

Fig. 3. Key Hole Biopsy. tients (Table 3 ). The final diagnosis was established by the initial sampling method in $42(91 \%)$ patients, including 22 (92\%) in the EUS-FNA group and 20 (91\%) in the KHB group $(P=0.999)$. A cross over examination was performed in $3(7 \%)$ of patients while one other patient refused cross-over. Final diagnosis after cross-over was established in 45 (98\%) (Table 4).

The final tissue diagnosis in the whole randomized population is shown in Table 3. GIST (70\%) and leiomyoma (15\%) were the most frequent SETs.

The mitotic activity was approximately specified only in $11(34 \%)$ of patients with preoperative diagnosis of GIST, including 7 (54\%) in the KHB group and 4 (21\%) in the EUS-FNA group. $(P=0.042)$ (Table 4$)$.

A total of 20 patients including 14 with GIST underwent surgical treatment. Postoperative tissue diagnosis corresponded to preoperative tissue diagnosis in 10 (91\%) patients in the KHB group and 9 (100\%) in the FNA group ( $P=0.999$ ) (Table 4$)$. In one case, the preoperative tissue diagnosis by KHB showed leiomyoma, whereas the definitive postoperative diagnosis was a GIST.

\section{DISCUSSION}

SET can be regarded as an umbrella term that encompasses lesions of the GI tract growing under the epithelial layer, regardless of their histology ${ }^{1,2}$. The clinical management and prognosis of SETs depend on correct preopera- tive diagnosis which is mostly based on imaging methods, including EUS (ref. ${ }^{8,21}$ ).

Based on EUS finding, The American Gastroenterological Association (AGA) recommends surgical resection of SETs $>3 \mathrm{~cm}$, originating from the muscularis propria layer, with hypoechoic or heterogeneous echostructure. On the other hand, SETs $<3 \mathrm{~cm}$ in size without EUS malignant signs can be periodically followed up, preferably by EUS (ref. ${ }^{21}$ ).

Although the contribution of EUS in the diagnosis of SETs is evident, low accuracy of EUS in the diagnosis of gastric SETs in the range of $46 \%-68 \%$ have been reported $^{9,22}$. For instance, Tae et al. reported that $43 \%$ of patients, who underwent surgical resection without preoperative pathological diagnosis, were confirmed to have benign lesions ${ }^{11}$. This and other trials showed that EUS alone may not be sufficient for making a diagnosis and that, in many cases, histological examination is necessary ${ }^{12,14,15,22}$. Such an examination requires deep biopsy techniques capable of reaching the layer of the upper GI wall beyond intact epithelium.

This study shows that both EUS-FNA and KHB have an equal potential to contribute to the diagnosis of upper gastrointestinal SETs (Table 4). As for EUS- FNA, it provided tissue sample sufficient for diagnosis of upper gastrointestinal SETs in $92 \%$ of cases. This finding is in agreement with Mekky' s study showing that EUS-FNA could obtain representative material for cytological assessment in $70-84 \%$ of SETs ${ }^{15}$. In another study, Gleeson 

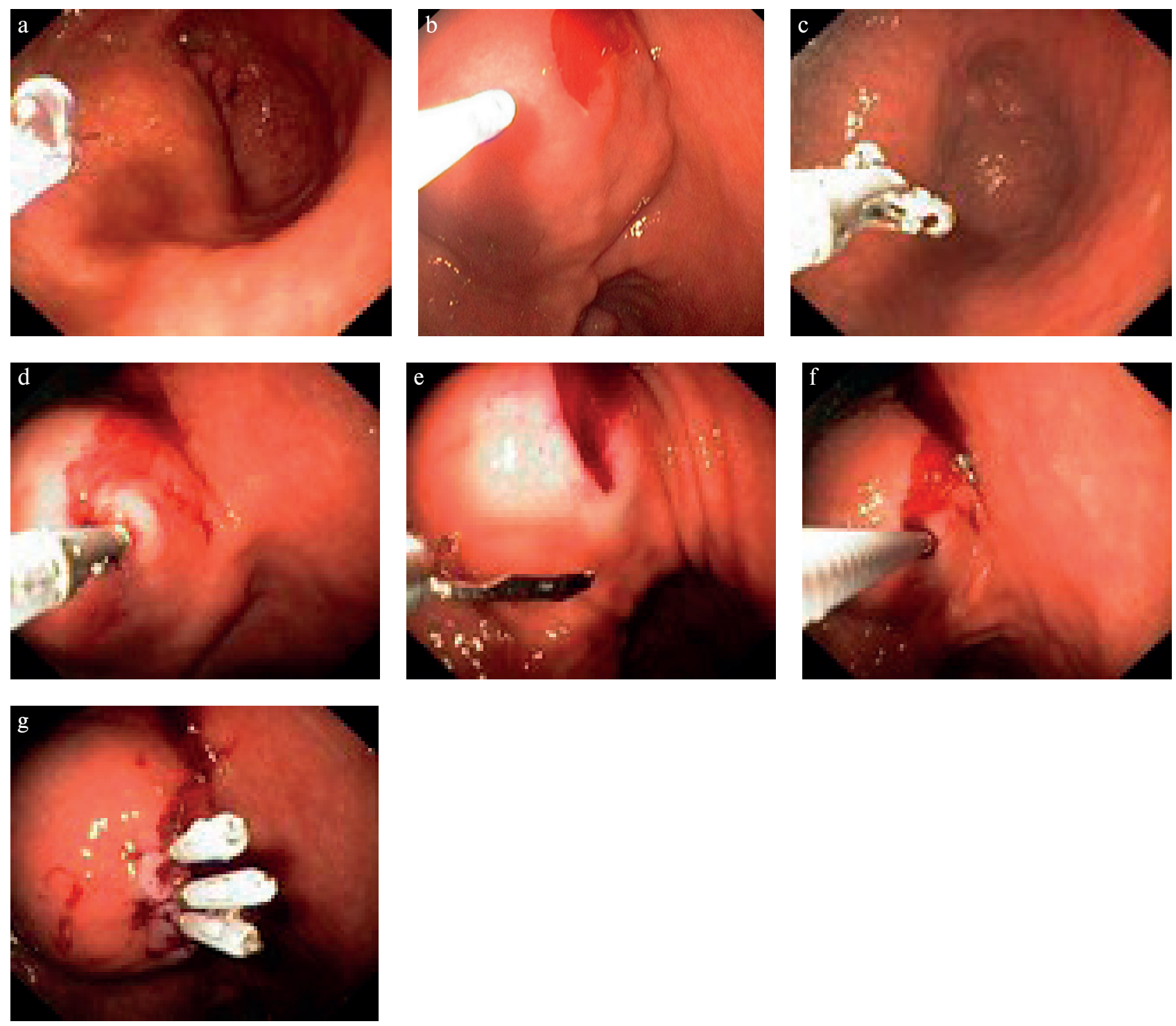

Fig. 4. Differents steps of Key Hole Biopsy. 4a. Pre-cutting knife before incision, 4b. Incision (KeyHole) maked by pre cutting knife, 4c. Opened forceps before biopsy, 4d. and 4e. Deep biopsy using forceps- samples are taken deeply, from different parts of the tumor, 4f. Opened endoscopic clips before closing the mucosal incision "Keyhole", 4g. The closed "Keyhole" by endoscopic clips.

et al. showed concordance in between invasive biopsy (EUS-FNA) results with corresponded surgical specimens in $96 \%$ (ref. ${ }^{14,23}$ ). Their finding is supported by the current study, which proved concordance in $100 \%$ cases.

Several other methods of EUS guided sampling are reported. Of these, trucut biopsy could improve results due to larger tissue sample. However, in a study by FernándezEsparrach G. et al EUS-trucut biopsy was no more accurate than EUS-FNA (ref. ${ }^{16}$ ). In order to increase the sample size, suction or a needle with a larger size could be used ${ }^{15,24}$.

There were no complications of EUS-FNA in our study. This result is consistent with the literature ${ }^{24,25}$. Despite the safety of EUS-FNA, it remains an expertdependent method $^{24}$.

As for the KHB, it enables the preoperative diagnosis of upper GI-SETs in $91 \%$ of cases. The correlation between preoperative tissue diagnosis using KHB and the postoperative histological diagnosis of SETs was $91 \%$, $P=0.999$. So far, we have found no other studies using KHB in the diagnosis of upper gastrointestinal SETs that would allow us to compare the results with the results in this study. As predicted by Grubel P in Endoscopy in 2010 (ref. ${ }^{19}$ ), the current trial confirmed that Keyhole biopsy is an alternative to fine-needle aspiration in the diagnostic of upper gastrointestinal subepithelial tumors (Table 4).

Mitotic index (MI) is an established prognostic criterion of GIST. In our study, mitotic activity (MA) could be estimated only in $21 \%$ and $54 \%$ in EUS FNA and KHB group, respectively. Moreover, the difference is not statistically significant (Fisher's Exact level $=0.295$ ), As a result, none of the study methods can be recommended for MA or MI evaluation.

The overall high correlation between preoperative and postoperative tissue diagnosis by either EUS-FNA or KHB method confirms the position of both studied 


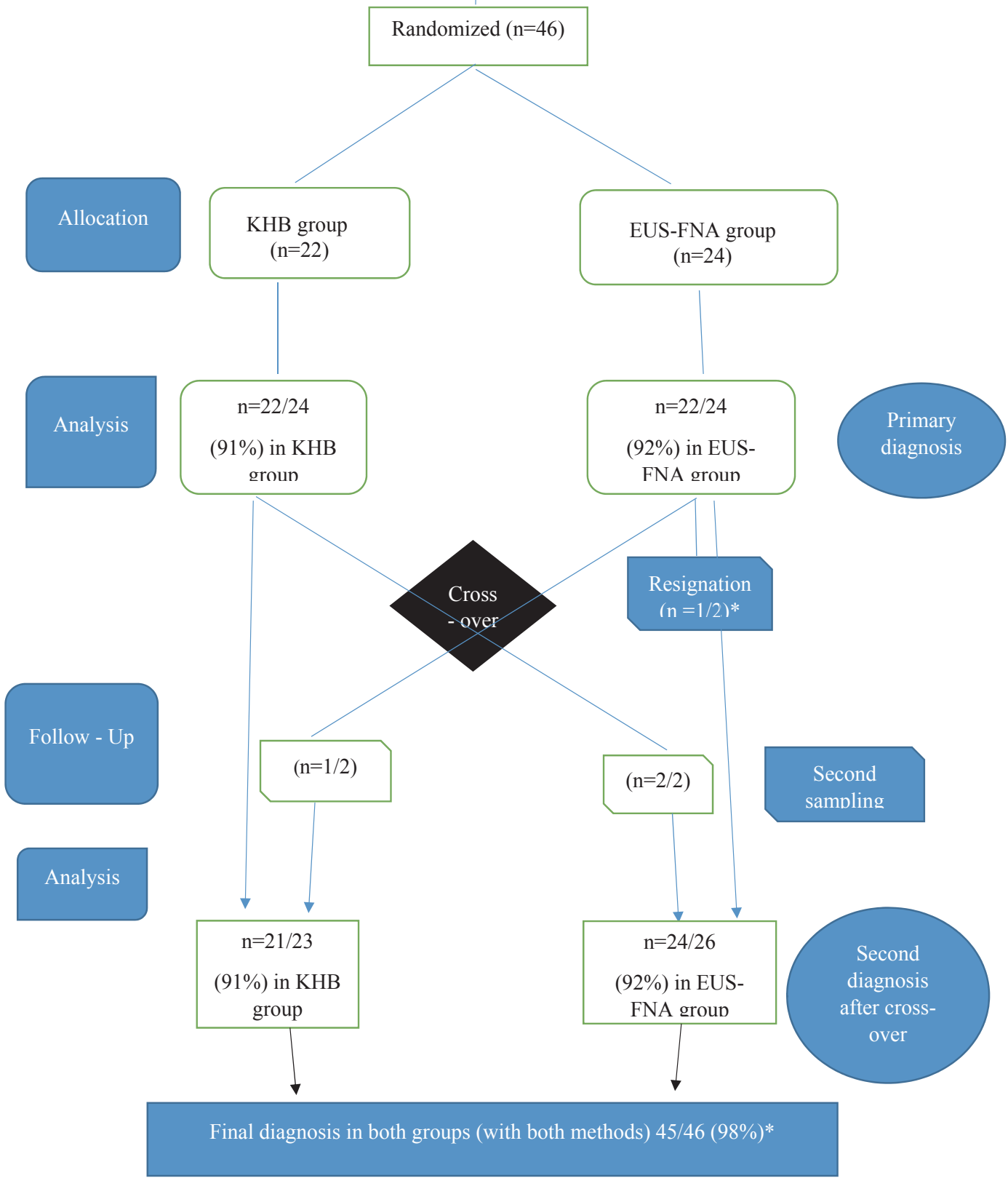

Fig. 5. Study flow diagram.

methods in the diagnostic algorithm of upper gastrointestinal SETs $>2 \mathrm{~cm}$ (Table 3 and 4 ). KHB is preferred in a clinical scenario with low availability of EUS-FNA.

For small $(<2 \mathrm{~cm})$ incidentally upper GI SETs a follow-up is probably a safe strategy, as shown by Hyun et al. ${ }^{3}$, although other studies have reported cases of small GIST $(1 \mathrm{~cm})$ with malignant potential and metastasis to distant organs ${ }^{22,26,27}$.

Our study has several limitations. The size of study sample is moderate. Rapid On-Site Evaluation (ROSE) of the samples was not available. However, based on the literature, ROSE can be advocated due to its potential for reducing the number of punctures ${ }^{24}$. Peritoneal seeding of malignant cells during deep tissue sampling is an issue. Although it was not the subject of our study, no signs of seeding was find in surgically treated patients.

\section{CONCLUSIONS}

Deep tissue sampling by EUS-FNA and KHB are equally effective in diagnostics of SETs of the upper gastrointestinal tract $\geq 2 \mathrm{~cm}$. Neither EUS-FNA nor KHB provide adequate tissue sample to determine mitotic index. 
Author contributions: VZ: manuscript writing, designed the study, main coordinator and biopsy performing; PFa: biopsy performing, approved final manuscript; PF, OM: contributed to the acquisition of data; EK, MH: assisted in analysis; KR: histological/cytological examination; DZ: histological/cytological examination, verification; MB: surgion- resection; AT: statistical analysis; MK: data acquisition, assisted in analysis; OU: planed study, biopsy performing, final approval.

\section{REFERENCES}

1. Humphris JL, Jones DB. Subepithelial mass lesions in the upper gastrointestinal tract. J Gastroenterol Hepatol 2008;23:556-66.

2. Hawes RH, Fockens P, Varadarajulu S, Young Kim E. Endosonography: Subepithelial lesions, 3th edition, Philadelphia, Saunders Elsevier, 2015: p. 112-128.

3. Song JH, Kim Sang G, Chung Su J, Kang Hae Y, Yang Sun Y, Kim Young S. Risk of progression for incidental small subepithelial tumors in the upper gastrointestinal tract. Endoscopy 2015;47:675-9.

4. Palazzo L, Landi B, Barthet M. Écho-endoscopie digestive: tumeurs sous-muqueuses de l'estomac. New York: Springer Paris Berlin Heidelberg, 2012, p. 125-143.

5. Rosch T. Endoscopic ultrasonography in upper gastrointestinal submucosal tumors: a literature review. Gastrointest Endosc Clin N Am 1995;5(3):609-14.

6. Hwang JH, Kimmey MB. The incidental upper gastrointestinal subepithelial mass. Gastroenterology 2004;126:301-7.

7. American society for gastrointestinal endoscopy (ASGA): role of EUS Guideline. Gastrointestinal endoscopy 2007;66(3):427-8.

8. Zoundjiekpon V, Urban O, Rydlo M, Ziak D, Falt P, Kundratova E, Hanousek M, Fojtik P, Mikolajek O. Diagnostika gastrointestinálnich stromalnich tumoru, Onkologie 2014:8(6):249-56. (In Czech)

9. Hwang JH, Saunders MD, Rulyak SJ, Shaw S, Nietsch H, Kimmey MB. A prospective study comparing endoscopy and EUS in the evaluation of Gl subepithelial masses. Gastrointest Endosc 2005;62:202-8.

10. Bucher P, Villiger P, Egger JF, Buhler LH, Morel P. Management of gastrointestinal stromal tumours: from diagnosis to treatment, Swiss Med WKLY 2004;134:145-53.

11. Miettinen M, Lasota J. Gastrointestinal stromal tumors - definition, clinical, histological, immunohistochemical, and molecular genetic features and differential diagnosis. Virchows Arch 2001;338:1-12.

12. Tae HJ, Lee HL, Lee KN, Jun DW, Lee OY, Han DS, Yoon BC, Choi HS, Hahm JS. Deep biopsy via endoscopic submucosal dissection in upper gastrointestinal subepithelial tumors: a prospective study. Endoscopy 2014;46:845-50.

13. Vaicekauskas R, Stanaitis J, Valantinas J. Efficacy of deep biopsy fo subepithelial lesions in the upper gastrointestinal tract. Wideochir Inne Tech Maloinwazyjne 2016;11(3):192-9.

14. Eckardt AJ, Wassef W. Diagnosis of subepithelial tumors in the GI tract. Endoscopy, EUS, and histology: bronze, silver, and gold standard? Gastrointest Endosc 2005;62:209-12.

15. Johns E, Binmoeller Kenneth F. Subepithelial lesions: A deeper look:: Gastrointestinal Endoscopy 2016,84(6):930-2.

16. Mekky MA, Yamao K, Sawaki A, Mizuno N, Hara K, Nafeh MA, Osman AM, Koshikawa T, Yatabe Y, Bhatia V. Diagnostic utility of EUS-guided FNA in patients with gastric submucosal tumors. Gastrointest Endosc 2010;71:913-9.

17. Fernández-Esparrach $G$, Sendino $O$, Solé $M$, Pellisé $M$, Colomo $L$, Pardo A, Martínez-Pallí G, Argüello L, Bordas JM, Llach J, Ginès A Endoscopic ultrasound-guided fine-needle aspiration and trucut biopsy in the diagnosis of gastric stromal tumors: a randomized crossover study. Endoscopy 2010;42:292-9.

18. Keswani RN, Nayar R, Mahajan A, Komanduri S. Touch preparation of jumbo forceps biopsies allows rapid adequacy assessment of subepithelial GI masses. Gastrointest Endosc 2011;74(2):411-4. doi: 10.1016/j.gie.2011.03.1238

19. Grubel P. Keyhole biopsy: an easy and better alternative to fineneedle aspiration or tru-cut biopsy of submucosal gastrointestinal tumors. Endoscopy 2010;42:685.

20. Wagh ST, Razvi NA. Marascuilo method of multiple comparisons (An analytical study of caesarean section delivery). Intl J Contemp Med Res2016;3(4):1137-40.

21. Hwang JH, Rulyak SD, Kimmey MB. American Gastroenterological Association Institute Technical Review on the Management of gastric subepithelial masses. Gastroenterology 2006;130:2217-8.

22. Karaca C, Turner BG, Cizginer S, Forcione D, Brugge W. Accuracy of EUS in the evaluation of small gastric subepithelial lesions. Gastrointest Endosc 2010;71:722-7.

23. Gleeson FC, Kerr SE, Kipp BR, Voss JS, Minot DM, Tu ZJ, Henry MR, Vasmatzis G, Cheville JC, Lazaridis KN, Levy MJ. Molecular cytology genotyping of primary and metastatic GI stromal tumors by using a custom 2-gene targeted next-generation sequencing panel with therapeutic intent. Gastrointest Endosc 2016;84(6):950-958.e3. doi: 10.1016/j.gie.2016.04.027

24. Polkowski M, Larghi $A$, Weynand B, Boustière $C$, Giovannini M, Pujol $B$, Dumonceau JM. Learning, techniques, and complications of endoscopic ultrasound (EUS)-guided sampling in gastroenterology: European Society of Gastrointestinal Endoscopy (ESGE) Technical Guideline Endoscopy 2012;44(02):190-206.

25. Dietrich CF, Jensse C. Endoscopic Ultrasound-Guided Sampling in Gastroenterology: European Society of Gastrointestinal Endoscopy Technical Guidelines, Endosc Ultrasound 2013;2(3):117-22.

26. Trupiano JK, Stewart RE, Misick C, Appelman HD, Goldblum JR Gastric Stromal tumors: a clinicopathologic study of 77 cases with correlation of features with non- aggressive and aggressive clinical behaviors. Am J Surg Pathol 2002;26:705-14.

27. Meesters B, Pauwels PAA, Pijnenburg AM, Vlasveld LT, Repelaer van Driel OJ. Metastasis in a "benign" duodenal stromal tumour. Eur J Surg Oncol 1998;24:334-5. 